Article

\title{
Concept Model to Measure the Thriving at Work (TAW): Developing and Applying
}

\author{
Khahan Na-Nan ${ }^{1, * \mathbb{D}}$, Suteeluck Kanthong ${ }^{1}$, Natthaya Wongsuwan ${ }^{2}$, Peerapong Pukkeeree ${ }^{3}$ \\ and Thitikul Sa-ngasilp ${ }^{2}$ \\ 1 Faculty of Business Administration, Rajamangala University of Technology Thanyaburi, \\ Pathum Thani 12110, Thailand; suteeluck_k@rmutt.ac.th \\ 2 Faculty of Business Administration, Ramkhamhaeng University, Bangkok 10240, Thailand; \\ natthaya@ru.ac.th (N.W.); thitikul.s@rumail.ru.ac.th (T.S.-n.) \\ 3 Faculty of Political Sciences, Ramkhamhaeng University, Bangkok 10240, Thailand; puk_peerapong@ru.ac.th \\ * Correspondence: khahan_n@rmutt.ac.th
}

Received: 7 July 2020; Accepted: 27 August 2020; Published: 30 August 2020

\begin{abstract}
The purposes of this study were to develop and validate an instrument to measure the thriving at work concept for vitality and learning dimensions in Thailand. Twelve items were selected to assess the thriving at work instrument developed from published research, concepts and theory. The instrument was applied as a cross-sectional study and data were collected as establishing factors to confirm and ascertain construct validity. Reliability was tested by measuring internal consistency. The instrument showed excellent reliability at 0.950 . Two factors, vitality and learning, were identified from confirmatory factor analysis. The thriving at work questionnaire is a new instrument in Thailand that comprehensively explores relevant dimensions to increase employees' understanding of vitality and learning.
\end{abstract}

Keywords: thriving at work; vitality; learning; thriving at work questionnaire

\section{Introduction}

\subsection{Why is Thriving at Work An Issue?}

Thriving at work (TAW) is an issue that now receives more attention concerning people's positive psychology-Jiang et al. [1]. The social concept of TAW was first proposed by Spreitzer et al. [2] in 2005. TAW is an important factor for assessing life quality and plays a significant role in an employee's work and occupation [3]. Thriving at work presents as different individual aspects and relates to a person's psychological state, manifesting as being energised and alive which are aspects of vitality and sense of learning [4].

Spreitzer, Sutcliffe, Dutton, Sonenshein and Grant [2] developed a prototype theory of TAW which explained particular characteristics of people (e.g., knowledge and positive affective), interaction (e.g., support and trust), contextual features (e.g., freedom to work in a convivial atmosphere) and agentic work behaviour (e.g., task orientation). Thriving at work transfers positive results for employees that do not occur from reducing or eliminating forces and cannot occur automatically. Rather, thriving at work is formed through personal preference and the relationship between an individual and a particular context. This contrasts with classical concepts of psychology, emphasising preceding hardship [5]; however, Spreitzer, Sutcliffe, Dutton, Sonenshein and Grant [2] argued that TAW can occur with or without hardship (p. 538).

Since Spreitzer, Sutcliffe, Dutton, Sonenshein and Grant [2] proposed the concept of thriving at work, this concept has drawn a lot of attention from western researchers and educators through 
many academic and research papers. According to western educators, thriving at work is defined as particular characteristics of people in relation to their targets, colleagues, and related environmental contexts with positive feelings [6-9]. In other words, thriving at work is perceived as a positive psychological status which includes employees' experience in learning and liveliness [10-12].

However, in Thailand, scant attention has been paid to the concept of TAW with no published studies in ThaiLIS-Thai Library Integrated System and Thai Journal Online: ThaiJo. ThaiLIS and Thaijo are resources of academic journals covering all fields of study in Thailand, supported by the Thailand Research Fund (TRF). 'Thriving at work' was used as a keyword to search for retrievals from these two resources and examine the available body of knowledge in terms of interested people as the starting point of this study. No articles concerning the concept of TAW were found. When the same keyword was used to search from Google, only one book published on TAW was found as a version translated from English to Thai in 2014 by a Thai educator from the original book entitled Shine: How to Survive and Thrive at Work by Baréz-Brown [13]. These findings show an extremely limited body of knowledge concerning TAW publications in Thailand. The researcher searched the keyword "Thriving" in Google and found only one paper of Luecha and Yoongtomg [14] studying about happiness at work with the consideration that thriving is people's feeling concerning happiness at work and it is regarded as one component of employees' happiness at work. In addition, the researcher interviewed experts in human resource development about causes why such a concept was not popular in Thai society and how thriving at work was perceived. This concept may be similar to the concept of career development or promotion, and close to the concepts of employees' job satisfaction and motivation. As a result, educators perceive these concepts as overlapping or the same issue. Chalermthanakijkosol [15] and Joungtrakul [16] agree that thriving at work is a psychological aspect of people to their jobs, determining by their incentives which drive them to work or behave to achieve their desired progress. Therefore, in Thai contexts, there remains a lack of knowledge and understanding concerning TAW concepts and principles. This knowledge gap requires filling to disseminate an understanding of TAW concepts and practices.

To systematically identify empirical concepts that are appropriate to the Thai situation, existing knowledge of TAW was applied to analyse factors, develop indicators and examine quality in terms of construct validity and reliability. The concept of TAW provides a useful and valuable scale of construct validity to determine positive psychology, self-efficacy, intelligence capital and organisational behaviour.

\subsection{Research Objectives and Questions}

Research to increase the body of knowledge of TAW is essential and urgent in Thailand where numbers of TAW research papers are significantly less than for studies in other fields. Furthermore, accurate, valid and reliable measures are required for each study of TAW to facilitate the availability of measuring tools for people interested in this field and to provide background information to improve the instruments according to the context of the study. Thus, based on the significances and problems of TAW, the current study aimed to develop a valid and reliable instrument for TAW measurement. The two main research questions are (a) "What are the constructs of TAW?" and (b) "How is the instrument consisting of such constructs confirmed for their effectiveness in measuring TAW?" This instrument will be useful for researchers, educators, students and the general public who are interested in further studies concerning TAW.

\section{Literature Review and Definitions of TAW}

TAW is a concept that has received attention dating back to Maslow [17]. Rogers [18] and Alderfer [19] focused on the psychological state of people who wanted to thrive in their life [20] or in their careers [21,22] depending on their particular path [23,24]. Employees who desire to achieve TAW status offer high performance [25] with job satisfaction [26] and positive engagement in the company $[4,9]$. TAW refers to the psychological state of a person concerning "vitality" and "learning" during work operation [2]. Vitality is an emotional state which makes employees energised and active 
in their work [27], while learning is the acquisition of knowledge and applied skills to form confidence and capabilities [28]. When people are thriving, they have a sense of progress that is transformed through learning (gaining more knowledge and understanding). People who desire to thrive are unsatisfied with their existing conditions; they attempt to improve themselves by actively seeking opportunities to learn and develop [26].

TAW also relates to other concepts such as flow, flourishing, subjective well-being, self-actualisation, resilience [4,9] and employee engagement [29]. TAW is distinctive from these other concepts since it focuses on positive experiences of human growth which manifest as vitality and learning [26]. All the aforementioned concepts are components of vitality which is the positive energy that effectively drives work, contrasting to a person who is thriving for a better life but cannot achieve this without learning [2].

Flow is a holistic sense of a person totally immersed in overall action. When a person enters the flow state, he/she experiences intense involvement and participation in all exposed and related activities [30]. TAW implies achieving optimal activities in terms of goodness, generativity, growth, resilience or a personal state to perform mental and social duties [31]. Subjective well-being is when a person assesses their whole life both mentally and emotionally and the positive feelings outweigh the negative ones [32]. TAW has similar characteristics to affective engagement and organisational norm as components of employee engagement developed by Schaufeli and Bakker [33]. TAW and employee engagement are closely linked to how a person devotes his/her energy to achieve work responsibilities. However, the distinction of TAW is to stimulate a person to learn how to develop himself/herself to become a potential person. Maslow's concept of self-actualisation refers to the achievements a person desires as a consequence of other prerequisite needs, whereas thriving occurs when a person's primary needs are not responded [2]. However, all behaviours mentioned above may occur either with or without external stimulations.

\subsection{Measurement of TAW}

Porath, Spreitzer, Gibson and Garnett [9] studied and developed a scale of TAW using samples from various occupations such as consultants, engineers and administrators. Twenty four items were developed and assessed using a six-point Likert scale with confirmatory factor analysis (CFA) used to statistically examine construct validity. They divided thriving into two dimensions as vitality and learning. The item reliability in both dimensions was higher than 0.70. Jaiswal and Dhar [34] conducted a study of TAW on employees in 35 organisations in India. They modified the scale of Porath, Spreitzer, Gibson and Garnett [9] into 10 items. Their scale assessed self-perception in two dimensions as vitality and learning; it examined confirmatory factors between the concepts and theories using empirical data. Findings indicated that their concepts and theories were consistent with the empirical data. Meanwhile, Sia and Duari [35] developed a self-assessment scale of 11 items. This scale was tested for reliability and validity with a resulting Cronbach's alpha value of 0.94 . Furthermore, Jiang, Jiang and Nielsen [1] created a scale of TAW in two dimensions with four items of vitality and three items of learning. All items were in the form of self-assessment and the resulting Cronbach's alpha coefficients were 0.95 and 0.86 respectively.

Thriving at work (TAW) refers to the mental status of people to perceive growth, work achievement and enthusiasm, or as positive behaviours in a psychological state to perform responsibility with the highest effectiveness. Thriving at work also refers to the perceptions or feelings of people with regard to vitality and learning. People with vital behaviours desire to release their energy through self-spirit to work successfully and perform actively, thereby maximising physical and mental energy. Learning refers to people's readiness to visualise new things in their surroundings, seek ways or methods to increasing their potential and the desire to continuously improve their capability.

Thriving at work leads to several benefits for organisations such as improved work performance [25], job satisfaction [26] and employee engagement [9,29]. Employees with perceived thriving at work behaviours regularly seek knowledge and learning resources to develop higher 
potentials. These people display enthusiasm and vitality to perform at their full potential; they are satisfied and motivated in their jobs. This leads to achieving work performance according to quantitative and qualitative targets. Employees adhere to company values and culture; they contribute maximum physical and mental energy to perform well and desire to remain with the organization.

\subsection{Requirement for Sample Size in Exploratory and Confirmatory Factor Analyses}

The empirical studies of Hogarty et al. [36], MacCallum et al. [37], MacCallum et al. [38], and Velicer and Fava [39] indicate the sample size consistently. The sample size for assessing coefficient accurately depends on the covariance of variables, the number of variables per one component, and interaction between these two aspects. If the commonness is high, the researcher will obtain an accurate evaluation of factor weights with a small sample size such as 100 samples. If the commonness is low, the sample size should be 500 . The previous principle rule indicates that the needed sample size is additional fuctions of the number of variables in the analysis and the suggested sample size are at 5,10, or even 20 times of the number of variables. However, Stevens (2012) indicates that the appropriate sample size in exploratory and confirmatory factor analysis should be 1 variable or item per 15 units.

Meanwhile, research by Hogarty, Hines, Kromrey, Ferron and Mumford [36] MacCallum, Widaman, Zhang and Hong [38] and MacCallum, Widaman, Preacher and Hong [37] have shown that more accurate estimates of loadings are obtained when the number of variables per factor is increased, even if the sample size stays the same. These researchers thus found that it was better to have more rather than fewer variables per factor. Of course, results are never simple, and the results from these studies were no exception. More specifically, the level of communality and the number of variables per factor interacted such that, if communalities were high (averaging 7), the number of variables per factor had little effect on the accuracy of estimation. Thus, variables with high communalities could compensate, to some extent, for having fewer variables per factor.

\subsection{Development and Tests of the TAW Scale}

\section{Phase 1: Development of items, test of content validity and test of scale reliability}

This phase developed and tested two steps as the development of the scale and scale validity and reliability. The initial scale was formed on the basis of the related literature to determine the existing concepts, theories and research concerning TAW [9,28,40,41]. Interviews were conducted at 20-30 min in length with each of six key informants as salespeople in small and medium enterprises. The purpose of the interview was to explore salespeople's behaviours concerning how they worked, how such behaviours were consistent with the theoretical concepts and how the initial items should be considered or improved to match the study contexts. Each key informant expressed their opinions about TAW. They were requested to define the characteristics of TAW. Most comments concurred with the related theoretical concepts. The informants divided TAW into two aspects. Firstly, employees' behaviours were full of vitality to release energy through self-spirit for working successfully. These people worked actively through their physical and mental energy; this description of behaviours was consistent with the vitality dimension in the existing theoretical concepts. Secondly, employees' behaviours were ready to learn new things by seeking new ways or procedures to develop their potentials. They wanted to embrace new ideas to continuously upgrade their potentials; this description of behaviours was consistent with the learning dimension in the existing theoretical concepts. When salespeople's behaviours were considered with the theory of vitality, important issues for forming the scale of TAW were adapted from the dimensions of vitality and learning. Appropriate scales for the items were selected in the form of a Likert scale with five levels as strongly disagree (1), disagree (2), indifferent (3), agree (4) and strongly agree (5).

The questionnaire was tested on content validation (Index of Item-Objective Congruence: IOC) which indicated the congruence between items and objectives. This value was used for examining the quality of each item to find out whether the developed questions covered the contents according to the 
objectives or not. Normally, IOC is calculated by using five experts' judgements to rate scores. Then, the researcher modifies each item according to the rating of the experts by adding the experts' rating scores for each item and dividing the sum by the number of the experts to obtain the IOC value of that item.

The content validity of the scale was tested by five experts in the fields of human resources, organisational behaviour, industrial psychology, marketing and testing and evaluation. The experts determined the consistency and accuracy of the items and also offered suggestions for improvement. The results yielded item-objective congruence (IOC) in the range of $0.8-1$, except for one item at less than 0.5. This item was deleted following the experts' suggestion. Rovinelli and Hambleton [42] suggested that items will have valid contents if IOC is higher than 0.80 . Thus, in this study, the results of content validity from the five experts were determined as statistically significant. Another test to determine the internal consistency of the scale involved 30 employees. The alpha coefficient was 0.950 with item-total correlation (ITC) at $0.665-0.852$ of the vitality dimension and $0.527-0782$ of the learning dimension. Henrysson [43] stated that ITC should be more than 0.40 , indicating that the items in this study had very good discriminative value. The Cronbach's alpha reliability coefficient was used to examine internal consistency and reliability of the measurement scale and assess the degrees of items as homogenous. Bonett and Wright [44] suggested that the alpha coefficient should be more than 0.60 . In this study, alpha coefficients were more than this criterion with vitality dimension at 0.914 and learning dimension at 0.853 . This indicated that the items had internal consistency with reliability regarding the measurement scale (Table 1 ).

Table 1. Item development and validity and reliability tests.

\begin{tabular}{|c|c|c|c|c|c|c|}
\hline Definition & Important Issue & Notation & Item & IOC & ITC & Alpha \\
\hline \multirow{7}{*}{$\begin{array}{l}\text { Vitality dimension refers to } \\
\text { people's working behaviours } \\
\text { which are full of vitality to } \\
\text { release energy through } \\
\text { self-spirit for working } \\
\text { successfully. These people } \\
\text { work actively through their } \\
\text { physical and mental energy. }\end{array}$} & - be vital & TAW 1 & $\begin{array}{l}\text { - I feel that my work } \\
\text { is vital. }\end{array}$ & 1 & 0.772 & 0.914 \\
\hline & $\begin{array}{l}\text { - want to } \\
\text { release energy }\end{array}$ & TAW 2 & $\begin{array}{l}\text { - I am ready to put my } \\
\text { physical energy } \\
\text { to work. }\end{array}$ & 1 & 0.691 & \\
\hline & - have self-spirit & TAW 3 & $\begin{array}{l}\text { - I am ready to put my } \\
\text { mental energy to work. }\end{array}$ & 1 & 0.837 & \\
\hline & - want to work & TAW 4 & $\begin{array}{l}\text { - I wait for the next day } \\
\text { to work. }\end{array}$ & 1 & 0.665 & \\
\hline & $\begin{array}{l}\text { - be alert and ready } \\
\text { to work }\end{array}$ & TAW 5 & $\begin{array}{l}\text { - I am alert and ready } \\
\text { to work. }\end{array}$ & 1 & 0.837 & \\
\hline & - be active & TAW 6 & $\begin{array}{l}\text { - I feel active } \\
\text { when working. }\end{array}$ & 0.80 & 0.852 & \\
\hline & $\begin{array}{l}\text { - have physical and } \\
\text { mental energy }\end{array}$ & * & $\begin{array}{l}\text { - I am physically } \\
\text { energetic and mentally } \\
\text { ready to work. }\end{array}$ & - & - & \\
\hline \multirow{6}{*}{$\begin{array}{l}\text { Learning dimension refers to } \\
\text { people's behaviours which are } \\
\text { ready to learn new things by } \\
\text { seeking new ways or } \\
\text { procedures to develop their } \\
\text { potentials. They want to } \\
\text { continuously embrace new } \\
\text { ideas to upgrade } \\
\text { their potentials. }\end{array}$} & $\begin{array}{l}\text { - learn things } \\
\text { around themselves }\end{array}$ & TAW 7 & $\begin{array}{l}\text { - I usually learn things } \\
\text { around me. }\end{array}$ & 1 & 0.527 & 0.853 \\
\hline & $\begin{array}{l}\text { - ready to learn new } \\
\text { things }\end{array}$ & TAW 8 & $\begin{array}{l}\text { - I am always ready to } \\
\text { learn new things. }\end{array}$ & 0.80 & 0.676 & \\
\hline & $\begin{array}{l}\text { - seek ways } \\
\text { to develop }\end{array}$ & TAW 9 & $\begin{array}{l}\text { - I like seeking new } \\
\text { ways or procedures } \\
\text { to develop myself. }\end{array}$ & 1 & 0.615 & \\
\hline & - develop oneself & TAW 10 & $\begin{array}{l}\text { - I want to develop } \\
\text { myself as much } \\
\text { as possible. }\end{array}$ & 1 & 0.550 & \\
\hline & - want to learn & TAW 11 & $\begin{array}{l}\text { - I want to learn how to } \\
\text { solve emerging } \\
\text { problems and obstacles. }\end{array}$ & 1 & 0.742 & \\
\hline & - want to improve & TAW 12 & $\begin{array}{l}\text { - I want to continuously } \\
\text { improve myself. }\end{array}$ & 1 & 0.782 & \\
\hline
\end{tabular}




\section{Phase 2: Exploratory factor analysis and confirmatory factor analysis}

This phase (1) reduced and classified the variables for reassessment using exploratory factor analysis (EFA) and (2) confirmed the variables and factors according to conceptual and theoretical structures using confirmatory factor analysis (CFA). Details are presented as follows.

Twelve items or variables were studied as TAW 1-12 (Table 1). Regarding sample size, Stevens [45] indicated that the ratio of sample units and the number of items should be 15:1. Here, 12 items were regarded as proportional for 180 sample units using a random convenience sampling method to recruit the samples. Salespeople working for small and medium enterprises in the Bangkok Metropolitan Region were invited to participate in the study. We selected homogeneous sampling because the justification for the homogeneous sampling of common types is that a theory of organizations can be built on the basis of one type and then tested and validated through replication with other types [46-48]. Emails were sent to the sales departments of the selected enterprises to request permission for their employees to complete and return the online questionnaire. Respondents who completed the questionnaires received coins to buy stickers in a chat Line Program. Female respondents made up $65 \%$, with males at $35 \%$. One-third of the respondents were $20-25$ years old (33.33\%), followed by $26-30(28.30 \%)$ and over $40(7.2 \%)$. Regarding their marital status, three quarters were single $(75.00 \%)$. Most respondents had a bachelor's degree $(78.30 \%)$ while the others had a master's degree and lower than a bachelor's degree (11.10\% and $10.60 \%$ respectively). About a quarter of the respondents had work experience of less than 1 year $(5.00 \%$ ) while about $21.70 \%$ had work experience ranging from 2 to 3 years and 6 to 10 years (16.10\% and $17.20 \%$ respectively). Regarding their work positions, $59.40 \%$ of respondents were officers followed by $22.8 \%$ senior officers, $9.40 \%$ supervisors and $8.30 \%$ managers.

The Kaiser-Meyer-Olkin (KMO) test was used to assess whether the sample size was sufficient for factor analysis KMO value was determined at 0.923 . Chan and Idris [49] indicated that a KMO value of more than 0.900 could be regarded as very high, with sample size considered as sufficient for conducting factor analysis. Moreover, Bartlett's test gave a chi-square value of 1837.523 with 66 degrees of freedom (df) at $p$-value $=0.000$. According to Watkins [50], Bartlett's test with statistical significance $(\mathrm{Sig}<0.05)$ indicated a significant correlation metric among some variables.

In addition, the researcher considered the eigenvalue of the factor analysis as the variation of all variables of each factor in the factor analysis. From the obtained common factors, the first factor was the factor to separate the variable's variation from other factors as much as possible. The covariance was also determined to measure the relationship between two or more variables.

For exploratory factor analysis, principal axis factoring was used to determine the total variance. The criteria of factor selection used in the analysis were eigenvalues at more than 1 to distinguish the two factors and percentage of accumulative variance at 74.521 of the total variance. Table 2 shows the eigenvalues of each factor in descending order. Following Kaiser's concept, eigenvalues were determined at more than 1 for the two factors, indicating that this analysis could extract two factors with eigenvalues of 62.832 and 11.689 as well as a covariance of 74.521. Varimax with Kaiser normalisation was used for axis rotation by squaring the weights in each column. In the factor matrix with maximum value, this method results in simple structured factors and specific factors, making the interpretation of factors more convenient [51]. After axis rotation, the extraction sums of squared loading variance changed slightly which could explain the total variance of the first factor at $39.149 \%$ and the second factor at $35.371 \%$.

Table 2 shows the results of exploratory factor analysis for items which were classified in two dimensions. The first dimension of learning included items TAW 7, TAW 8, TAW 9, TAW 10, TAW 11 and TAW 12 with range of factor weight $0.783-0.845$. The second dimension of vitality included items TAW 1, TAW 2, TAW 3, TAW 4, TAW 5 and TAW 6 with range of factor weight $0.686-0.855$. Kyriazos [52] and Turner and Carlson [53] stated that an appropriate exploratory factor weight should be over 0.500. Similarly, Hair et al. [54] considered that the factor weight should be over 0.500, while a value of 0.700 or over represented a very good weight. In this study, factor weights were between 0.686 and 0.855 , indicating consistency for the criteria of exploratory factor analysis. 
Table 2. Exploratory factor analysis (EFA) results of the thriving at work (TAW) questionnaire.

\begin{tabular}{ccc}
\hline \multirow{2}{*}{ Question } & \multicolumn{2}{c}{ Factor Weight } \\
\cline { 2 - 3 } & I & II \\
\hline TAW 1 & & 0.824 \\
TAW 2 & & 0.849 \\
TAW 3 & & 0.855 \\
TAW 4 & & 0.755 \\
TAW 5 & & 0.686 \\
TAW 6 & & 0.697 \\
TAW 7 & 0.783 & \\
TAW 8 & 0.795 & \\
TAW 9 & 0.804 & \\
TAW 10 & 0.845 & \\
TAW 11 & 0.798 & \\
TAW 12 & 0.822 & \\
\hline
\end{tabular}

Note: Extraction method: Principal Component Analysis. Rotation method: Varimax with Kaiser normalisation.

\section{Phase 3: Major study for scale validation}

This phase validated the factor structure using structural equation modelling (SEM) and confirmatory factor analysis (CFA) on a new dataset following a multi-criteria strategy.

In the confirmatory test of model structure with two factors obtained from factor analysis, CFA was used for a new sample group of 180 salespeople. Online questionnaires were sent to the participants. In this phase, most respondents were female $(74.40 \%)$ and the rest were male $(25.60 \%)$. Of these, $38.30 \%$ were $26-30$ years old, followed by $20-25$ years (30.60\%), 31-35 years old ( $15.60 \%), 36-40$ years old $(10.00 \%)$ and more than 40 years old $(5.6 \%)$. About three-quarters of the respondents were single $(70.60 \%)$, while the rest were married and divorced. Regarding their educational level, $70.60 \%$ had a bachelor's degree, whereas the others had a master's degree and lower than a bachelor's degree $(17.80 \%$ and $11.70 \%$ respectively). About a quarter of the respondents had work experience $4-5$ years (26.10\%) with $2-3$ years $(23.80 \%), 6-10$ years $(17.80 \%)$, more than 10 years $(16.70 \%)$ and less than 1 year $(15.60 \%)$. Most of them were employees $(47.80)$, while the rest were senior officers $(38.90 \%)$, supervisors $(8.90 \%)$ and managers $(4.40 \%)$. Participants were requested to respond to the 12 items which mostly conformed to their behaviours. The response format was in the form of a five-point Likert scale (ranged in ascending order). The appropriate types of factors were tested to determine whether they were real according to theoretical concepts and consistent with the empirical data. Consistency indexes included the chi-square fit index, the goodness-of-fit index (GFI), adjusted goodness-of-fit index (AGFI), comparative fit index (CFI), root-mean-square residual (RMR), normed fit index (NFI) and root-mean-square error of approximation (RMSEA) (Byrne, 2016; Kline, 2015). Data analyses were performed with IBM SPSS AMOS 21.

First- and second-order confirmatory factors were analysed. First-order confirmatory factor analyses were tested for the construct validity of the items to determine whether TAW 1, TAW 2, TAW 3, TAW 4, TAW 5 and TAW 6 were factors of vitality latent variables and whether TAW 7, TAW 8, TAW 9, TAW 10, TAW 11 and TAW 12 were factors of learning latent variables. Second-order confirmatory factor analyses tested whether the two latent variables as vitality and learning in the first order were factors of TAW. Figure 1 illustrates the model fit and empirical data with $\chi^{2}=45.397$, $\mathrm{df}=41, p$-value $=0.294, \mathrm{GIF}=0.958, \mathrm{AGIF}=0.921, \mathrm{CFI}=997, \mathrm{TLI}=0.995, \mathrm{RMR}=0.023, \mathrm{NFI}=0.951$ and RMSEA $=0.024$. Results conformed to the criteria of Kline [55] who suggested that $\chi^{2} / \mathrm{df}$ should be less than 2, $p$-value should be more than 0.05 and GFI, AGFI, TLI and CFI should be more than 0.900 or close to 1.000, whereas RMSEA and RMR should not exceed 0.050 . 


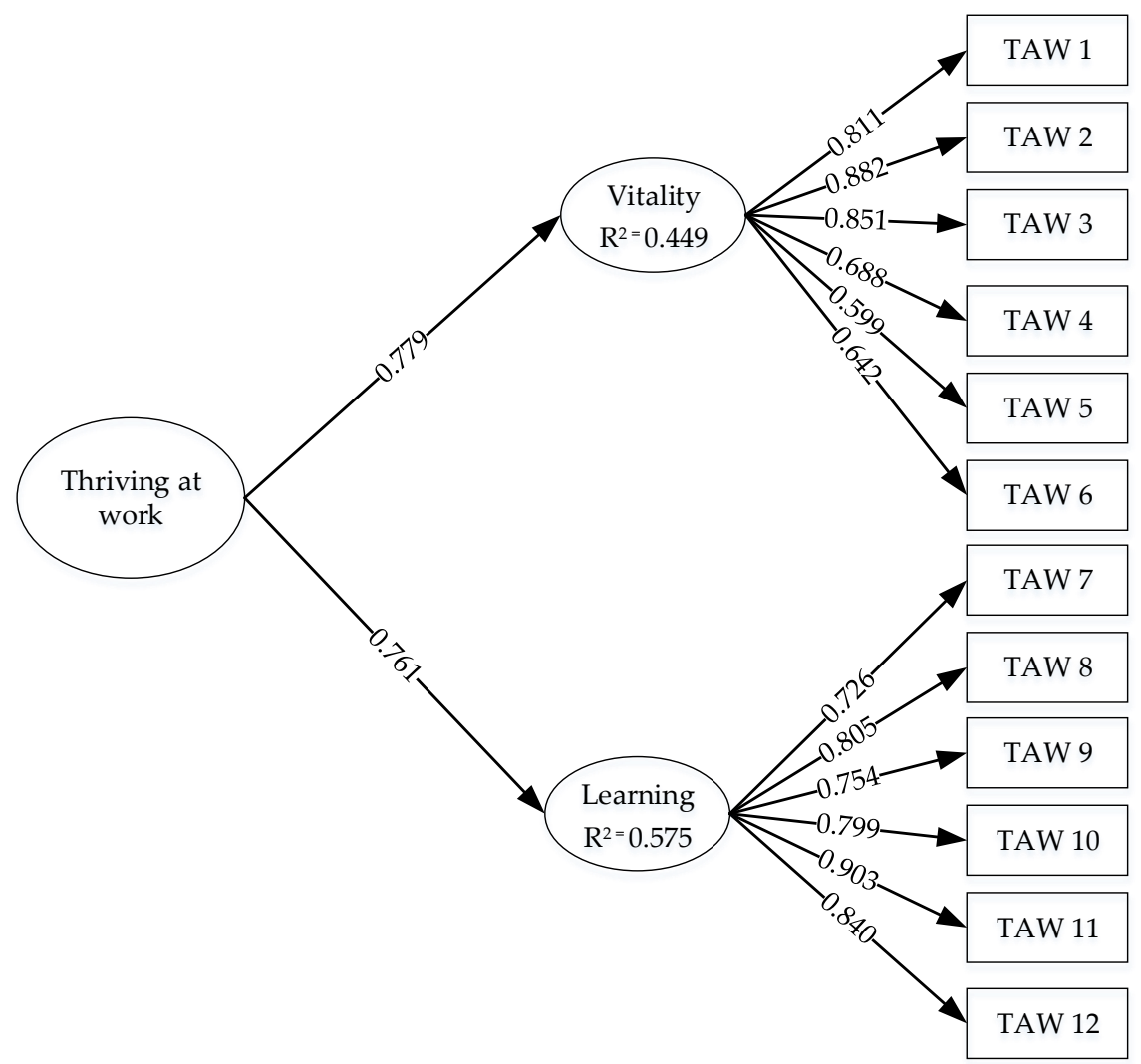

Figure 1. TAW structural model. $\chi^{2}=45.397, p$-value $=0.294, \mathrm{GIF}=0.958, \mathrm{AGIF}=0.921, \mathrm{CFI}=997$, $\mathrm{TLI}=0.995, \mathrm{RMR}=0.023, \mathrm{NFI}=0.951$ and $\mathrm{RMSEA}=0.024$.

Twelve items were tested using the CFA method. Results indicated that vitality (Factor I), including items TAW 1-TAW 6 showed factor weights $0.599-0.882$ and $R^{2} 0.359-0.779$, while learning (Factor II) including items TAW 7-TAW 12 had factor weights $0.726-0.903$ and $\mathrm{R}^{2} 0.527-0.816$. Results of the second-order confirmatory factor analysis with two factors of vitality and learning had factor weights 0.670 and 0.758 respectively (Table 3). Factor weights in the first and second orders of this research were determined as statistically significant for all values because the factor weights were over 0.300 $(p<0.050)[56,57]$.

Table 3. Construct validity of first and second-order CFA.

\begin{tabular}{|c|c|c|c|c|c|c|c|c|c|}
\hline \multirow{2}{*}{\multicolumn{2}{|c|}{$\begin{array}{c}\text { Latent } \\
\text { Factors/Questions }\end{array}$}} & \multicolumn{4}{|c|}{ First Order CFA Construct Validity } & \multicolumn{4}{|c|}{ Second-Order CFA Construct Validity } \\
\hline & & $\begin{array}{l}\text { Factor } \\
\text { Loading }\end{array}$ & $\mathbf{R}^{2}$ & CR & AVE & $\begin{array}{l}\text { Factor } \\
\text { Loading }\end{array}$ & $\mathbf{R}^{2}$ & CR & AVE \\
\hline \multirow{6}{*}{$\begin{array}{l}\text { Factor I } \\
\text { Vitality }\end{array}$} & TAW 1 & $0.811^{* * *}$ & 0.657 & \multirow{6}{*}{0.888} & \multirow{6}{*}{0.576} & \multirow{6}{*}{$0.670 * * *$} & \multirow{6}{*}{0.449} & \multirow{12}{*}{0.676} & \multirow{12}{*}{0.511} \\
\hline & TAW 2 & $0.882 * * *$ & 0.779 & & & & & & \\
\hline & TAW 3 & $0.851^{* * *}$ & 0.724 & & & & & & \\
\hline & TAW 4 & $0.688^{* * *}$ & 0.473 & & & & & & \\
\hline & TAW 5 & $0.599 * * *$ & 0.359 & & & & & & \\
\hline & TAW 6 & $0.642 * * *$ & 0.412 & & & & & & \\
\hline \multirow{6}{*}{$\begin{array}{l}\text { Factor II } \\
\text { Learning }\end{array}$} & TAW 7 & $0.726^{* * *}$ & 0.527 & \multirow{6}{*}{0.915} & \multirow{6}{*}{0.645} & \multirow{6}{*}{$0.758^{* * *}$} & \multirow{6}{*}{0.575} & & \\
\hline & TAW 8 & $0.805^{* * *}$ & 0.648 & & & & & & \\
\hline & TAW 9 & $0.754^{* * *}$ & 0.568 & & & & & & \\
\hline & TAW 10 & $0.779 * * *$ & 0.607 & & & & & & \\
\hline & TAW 11 & $0.903^{* * *}$ & 0.816 & & & & & & \\
\hline & TAW 12 & $0.840^{* * *}$ & 0.705 & & & & & & \\
\hline
\end{tabular}

Note: ${ }^{* * *}$ indicates significance level at 0.001 . 
Regarding composite reliability (CR) of the construct validity, confirmatory factor analyses results for vitality and learning were 0.888 and 0.915 (Table 3), passing the criteria of Hair et al. (2010) who suggested that factor reliability should be more than 0.70 . The average variance extracted (AVE) ranged between 0.576 and 0.645 , conforming to the criteria of Zait and Bertea [58] who suggested that the average variance extracted should be more than 0.50 to be considered as statistically significant. Results from the instrument for convergent validity measurement revealed the robustness of the structural model. The discriminant validity of the instrument was tested for accuracy in measuring the studied attributes according to the theoretical concepts. The validity test was conducted following Fornell and Larcker [59] who suggested that the square root of the AVE value should be higher than the relationship between rows and columns. Results showed that the validity analysis conformed to the criteria as shown in Table 4.

Table 4. Discriminant validity analysis.

\begin{tabular}{ccccc}
\hline Variable & Mean & SD & Vitality & Learning \\
\hline Vitality & 3.611 & 0.690 & $(0.758)$ & \\
Learning & 4.233 & 0.637 & $0.551^{* *}$ & $(0.803)$
\end{tabular}

The alpha coefficient after questionnaire validity was 0.950

Note: ${ }^{* *}$ indicates significance level at 0.01 , values in parentheses represent the square root of AVE.

\section{Discussion: A TAW Instruments and Open Innovation}

TAW of employees can be described as psychological experience during the growth of positive capabilities and power to stimulate and perform work effectively. Empirical data from this study suggested that the two dimensions of vitality and learning conformed to TAW concepts, theories and previous research. Thus, if employees have a sense of TAW, this will manifest as lively behaviours in their work, release their energy through self-spirit to achieve their work and actively perform their duties with enhanced physical and mental energy $[1,2,9,29,34,60]$. These behaviours can be measured using six of the developed items. These items were tested for reliability and content validity by five experts and scale results from exploratory and confirmatory factor analyses conformed well with the empirical evidence. The vitality scale was developed to test and measure the positive thinking and actions of salespeople according to the concepts and theories of Jaiswal and Dhar [34], Jiang, Jiang and Nielsen [1], Porath, Spreitzer, Gibson and Garnett [9], Spreitzer, Sutcliffe, Dutton, Sonenshein and Grant [2] and Spreitzer, Lam and Fritz [29]. The learning scale consisted of six items that were statistically tested for content validity and reliability before use. They were examined using both exploratory and confirmatory factor analyses to test the validity of the instrument. Our results conformed to all criteria and the relationship capital of the scale was determined as highly accurate and reliable. The employees manifested their readiness to learn new things, seek new working methods or procedures to perform their work assignments effectively and desired to continuously develop and upgrade their potential $[1,2,9,29,34,61]$. The developed scale conformed to the related concepts and theories of previous research to comprehensively measure learning capital.

\section{Conclusions}

The scale is developed to test with various occupations to reflect the overall non-specific aspects. The developed TAW scale is compact with 12 items so it is conveniently used for collecting data and responding to the questionnaire. The previous scale of Porath, Spreitzer, Gibson and Garnett [9] includes 24 items that take time to complete, so respondents may be bored or respond nonchalantly to the questionnaire, resulting in unreliable and invalid data. However, the developed scale is developed with the coverage of concepts and theories. The items are developed by synthesizing previous concepts and theories and by identifying keywords to develop the items to cover the previous concepts and theories. 
Regarding the contexts of the scale development, it is developed in the Thai context which is closest to Asian contexts. Therefore, the scale can be applied and modified to use in similar contexts or occupations. However, in comparison with the previous scales, most of them are developed in western contexts with different cultures, lifestyles and works so these scales are reliable and valid more in western contexts than in Asian contexts. The samples in this scale development were salespeople who were closely similar and homogeneous. Therefore, the obtained results are more reliable than the samples in various occupations because the items may not reflect all occupations. Compared to previous scales, the samples in the scale developments were postgraduate students from different organizations and responsibilities so the scale was appropriate for general aspects rather than specific to each career.

Riaz et al. [62] studied the effects of thriving at work on innovative behaviour with the mediator of organisational support. They found that perceived thriving at work had a direct effect on work innovative behaviour and an indirect effect on work innovative behaviour through the mediator of organisational support. In the same vein, Wang et al. [63] found that perceived thriving at work functioned as the mediator between servant leadership and work innovative behaviour. Leaders should support employees' perceived thriving at work to drive and promote innovative behaviours. Empirical research results revealed that promoting the concept of thriving at work leads to positive results of innovative behaviours. Open innovation encourages thriving at work that promotes and creates new ideas for services or products. Therefore, thriving at work is a contributing factor for new open innovation, development and discovery [64]. Thriving at work and open innovation encourage the outflow of knowledge and accelerate internal innovation $[65,66]$. The concept of thriving at work is an essential variable to activate open innovation and increase company prosperity [67,68].

Employees with perceived TAW are constantly learning and they express vitality when carrying out their work and responsibilities [9]. This helps them to diversify their knowledge and innovation. Learning and vitality support and promote enthusiasm for employees to work effectively, by encouraging them to source both internal and external knowledge to create services or products that benefit the company [69]. Therefore, creating or encouraging employees to demonstrate TAW will help to reduce operational costs and lead to innovative research and development. TAW will also increase the potential for employee development and build partnerships to increase co-creation, expand innovative concepts more efficiently and discover new ways to best apply work systems [66]. TAW will lead to creative innovation and a better understanding of the complexity of company operations. This will result in the creation of open innovation and enhance continued future prosperity.

\subsection{Theoretical Implications}

Academics can use our findings to describe employees' perceived TAW in organisations that can occur in two dimensions as vitality and learning [1,2,9,29,34]. Employees who want to thrive manifest their vital behaviours. This releases energy to work actively, pay attention to work details and concentrate on performing responsibly to achieve goals. These people also display a readiness to learn new things around them by seeking new working methods or procedures to improve their skills. They also desire to continuously develop and upgrade their potential to perform more effectively. Our results will help educators to explain the phenomenon of emerging TAW of salespeople or those in other related careers, especially in Thai or Asian contexts. These twelve items have been intensively tested on dimensions of vitality and learning but they should be further studied to become a new scale of employees' TAW in small and medium Thai enterprises. Academics and researchers can use this TAW scale as an initiator in their studies to measure TAW levels of employees or test other independent or dependent as well as moderators that influence or are influenced as mediators to other factors. The obtained data can be used to explain the characteristics and phenomena of employees' perceived TAW with more accurate and efficient clarity. 


\subsection{Practical Implications}

Our study extends the scope of existing concepts and theories regarding the measurement of TAW by adapting Western contexts to Thai and Asian situations. This developed scale was carefully tested for content validity and reliability and can be used by managers, human resource developers, organisational behaviourists and general practitioners to measure levels of employees' perceived TAW. Results can be analysed to determine existing levels and find ways to stimulate, enhance and support employees to manifest their TAW behaviours.

Human resource departments can use the scale of thriving at work to measure employees' behaviors to find out the level of overall thriving at work in employees. The scale can also be used for determining the levels of sub-components of liveliness and learning. Human resource departments can use the analysis results for diagnosing and considering the arrangement of development or training for each employee to be on their appropriate career path as well as to encourage employees to gain more potentials for their job responsibilities.

Our findings show that vitality and learning of employees can be measured as indicators of perceived TAW. Therefore, management and human resource development departments should support, enhance and drive employees to realise their potentials and continuously learn and upgrade their work performances.

\subsection{Research Limitations}

Similar to other studies in this domain [70], the research limitations should also be considered. The scale of thriving may be influenced by the bias of the respondents' perceptions through using a cross-sectional study and self-assessment. The results may also be biased by the research method.

Biases may occur from the respondents' perception, the research methods, and the scale tests in this study, which was examined in the contexts of the salespeople in the small and medium enterprises. This makes applying the scale in different study contexts difficult, and this is also considered as one limitation of this study, which may affect the study's validity and reliability. Aguinis et al. [71] and Na-Nan et al. [72] suggest that, in social science research, researchers should be aware and recognize contexts of the study such as language, society, culture, value, norm, and economic system. These factors can possibly influence the validity and reliability of the developed scale. Therefore, variance may occur in the studies of various cultures and contexts. To improve the scale's reliability, the scales should be tested with samples that differ in terms of languages, societies, cultures, values, norms, and economic system.

Author Contributions: Conceptualization, K.N.-N. and S.K.; methodology, K.N.-N.; software, P.P.; validation, K.N.-N., S.K., N.W., P.P. and T.S.-n.; formal analysis, K.N.-N.; investigation, N.W., P.P. and T.S.-n.; resources, S.K.; data curation, K.N.-N.; writing-original draft preparation, K.N.-N.; writing-review and editing, K.N.; visualization, K.N.-N.; supervision, K.N.-N.; project administration, K.N.-N.; funding acquisition, K.N.-N. All authors have read and agreed to the published version of the manuscript.

Funding: This research received no external funding.

Conflicts of Interest: The authors declare no conflict of interest.

\section{References}

1. Jiang, Z.; Jiang, Y.; Nielsen, I. Workplace thriving in China. Int. J. Manpow. 2019, 40, 979-993. [CrossRef]

2. Spreitzer, G.; Sutcliffe, K.; Dutton, J.; Sonenshein, S.; Grant, A.M. A socially embedded model of thriving at work. Organ. Sci. 2005, 16, 537-549. [CrossRef]

3. Zhai, Q.; Wang, S.; Weadon, H. Thriving at work as a mediator of the relationship between workplace support and life satisfaction. J. Manag. Organ. 2017, 1, 1-17. [CrossRef]

4. Spreitzer, G.; Bacevice, P.; Garrett, L. Workplace design, the physical environment, and human thriving at work. In Organizational Behaviour and the Physical Environment; Ayoko, O.B., Neal, M.A., Eds.; Routledge: London, UK, 2019; pp. 235-250. 
5. Kleine, A.-K.; Rudolph, C.W.; Zacher, H. Thriving at work: A meta-analysis. J. Organ. Behav. 2019, 40, 973-999. [CrossRef]

6. Chang, W.; Busser James, A. Hospitality career retention: The role of contextual factors and thriving at work. Int. J. Contemp. Hosp. Manag. 2020, 32, 193-211. [CrossRef]

7. Chiamaka, O.J.-A.; Stephen, E.I.; Collins, I.N. Leader-member Exchange and Transformational Leadership Style: A Prediction to Thriving at Work. Asian J. Adv. Res. Rep. 2020, 12, 37-43. [CrossRef]

8. Liu, Y.; Xu, S.; Zhang, B. Thriving at work: How a paradox mindset influences innovative work behavior. J. Appl. Behav. Sci. 2020, 56, 347-366. [CrossRef]

9. Porath, C.; Spreitzer, G.; Gibson, C.; Garnett, F.G. Thriving at work: Toward its measurement, construct validation, and theoretical refinement. J. Organ. Behav. 2012, 33, 250-275. [CrossRef]

10. Xu, A.J.; Loi, R.; Chow, C.W.C. What threatens retail employees' thriving at work under leader-member exchange? The role of store spatial crowding and team negative affective tone. Hum. Resour. Manag. 2019, 58, 371-382. [CrossRef]

11. Sun, Y.; Zhu, M.; Zhang, Z.J. How Newcomers' Work-Related Use of Enterprise Social Media Affects Their Thriving at Work-The Swift Guanxi Perspective. Sustainability 2019, 11, 2794. [CrossRef]

12. Abid, G.; Contreras, F.; Ahmed, S.; Qazi, T. Contextual factors and organizational commitment: Examining the mediating role of thriving at work. Sustainability 2019, 11, 4686. [CrossRef]

13. Baréz-Brown, C. Shine: How to Survive and Thrive at Work; Penguin: New York, NY, USA, 2012.

14. Luecha, T.; Yoongtomg, K. Concept and Measurement of Happiness at Work. Acad. J. Phetchaburi Rajabhat Univ. 2017, 19, 9-18.

15. Chalermthanakijkosol, K. Acee Management International limited. Bangkok, Thailand. Personal Interview, 29 May 2020.

16. Joungtrakul, J. Far East University, Eumseong-gun, Chungcheongbuk-do 27601, Korea. Personal Interview, 29 July 2019.

17. Maslow, A.H. A theory of human motivation. Psychol. Rev. 1943, 50, 370-396. [CrossRef]

18. Rogers, C. On Becoming a Person: A Therapist's View of Psychotherapy; Constable: London, UK, 1961.

19. Alderfer, C. Existence, Relatedness, and Growth; Human Needs in Organizational Settings; Free Press: New York, NY, USA, 1972.

20. Saakvitne, K.W.; Tennen, H.; Affleck, G. Exploring thriving in the context of clinical trauma theory: Constructivist self development theory. J. Soc. Issues 1998, 54, 279-299. [CrossRef]

21. Calhoun, L.G.; Tedeschi, R.G. Beyond recovery from trauma: Implications for clinical practice and research. J. Soc. Issues 1998, 54, 357-371. [CrossRef]

22. Ickovics, J.R.; Park, C.L. Paradigm shift: Why a focus on health is important. J. Soc. Issues 1998, 54, $237-244$. [CrossRef]

23. Halbesleben, J.R.B.; Harvey, J.; Bolino, M.C. Too engaged? A conservation of resources view of the relationship between work engagement and work interference with family. J. Appl. Psychol. 2009, 94, 1452-1465. [CrossRef]

24. Thomas, S.P.; Hall, J.M. Life trajectories of female child abuse survivors thriving in adulthood. Qual. Health Res. 2008, 18, 149-166. [CrossRef]

25. Paterson, T.A.; Luthans, F.; Jeung, W. Thriving at work: Impact of psychological capital and supervisor support. J. Organ. Behav. 2014, 35, 434-446. [CrossRef]

26. Niessen, C.; Sonnentag, S.; Sach, F. Thriving at work-A diary study. J. Organ. Behav. 2012, 33, $468-487$. [CrossRef]

27. Bensemmane, S.; Ohana, M.; Stinglhamber, F. Team justice and thriving: A dynamic approach. J. Manag. Psychol. 2018, 33, 229-242. [CrossRef]

28. Li, M.; Liu, W.; Han, Y.; Zhang, P. Linking empowering leadership and change-oriented organizational citizenship behavior: The role of thriving at work and autonomy orientation. J. Organ. Chang. Manag. 2016, 29, 732-750. [CrossRef]

29. Spreitzer, G.M.; Lam, C.F.; Fritz, C. Engagement and human thriving: Complementary perspectives on energy and connections to work. In Work Engagement: A Handbook of Essential Theory and Research; Bakker, A.B., Leiter, M.P., Eds.; Psychology Press: London, UK, 2010; pp. 132-146.

30. Piniel, K.; Albert, Á. Motivation and flow. In The Palgrave Handbook of Motivation for Language Learning; Springer: Berlin, Germany, 2019; pp. 579-597. 
31. Yang, Y.; Li, Z.; Liang, L.; Zhang, X. Why and when paradoxical leader behavior impact employee creativity: Thriving at work and psychological safety. Curr. Psychol. 2019, 1-12. [CrossRef]

32. Kibler, E.; Wincent, J.; Kautonen, T.; Cacciotti, G.; Obschonka, M. Can prosocial motivation harm entrepreneurs' subjective well-being? J. Bus. Ventur. 2019, 34, 608-624. [CrossRef]

33. Schaufeli, W.B.; Bakker, A.B. Defining and measuring work engagement: Bringing clarity to the concept. In Work Engagement: A Handbook of Essential Theory and Research, Bakker, A.B., Leiter, M.P., Eds.; Pshychology Press: New York, NY, USA, 2010; Volume 12, pp. 10-24.

34. Jaiswal, N.; Dhar, R. The influence of servant leadership, trust in leader and thriving on employee creativity. Leadersh. Organ. Dev. J. 2017, 38, 2-21. [CrossRef]

35. Sia, S.K.; Duari, P. Agentic work behaviour and thriving at work: Role of decision making authority. Benchmarking Int. J. 2018, 25, 3225-3237. [CrossRef]

36. Hogarty, K.Y.; Hines, C.V.; Kromrey, J.D.; Ferron, J.M.; Mumford, K.R. The quality of factor solutions in exploratory factor analysis: The influence of sample size, communality, and overdetermination. Educ. Psychol. Meas. 2005, 65, 202-226. [CrossRef]

37. MacCallum, R.C.; Widaman, K.F.; Preacher, K.J.; Hong, S. Sample size in factor analysis: The role of model error. Multivar. Behav. Res. 2001, 36, 611-637. [CrossRef]

38. MacCallum, R.C.; Widaman, K.F.; Zhang, S.; Hong, S. Sample size in factor analysis. Psychol. Methods 1999, 4, 84-99. [CrossRef]

39. Velicer, W.F.; Fava, J.L. Affects of variable and subject sampling on factor pattern recovery. Psychol. Methods 1998, 3, 231-251. [CrossRef]

40. Abid, G.; Sajjad, I.; Elahi, N.S.; Farooqi, S.; Nisar, A. The influence of prosocial motivation and civility on work engagement: The mediating role of thriving at work. Cogent Bus. Manag. 2018, 5, 1-19. [CrossRef]

41. Nawaz, M.; Abid, G.; Arya, B.; Bhatti, G.A.; Farooqi, S. Understanding employee thriving: The role of workplace context, personality and individual resources. Total Qual. Manag. Bus. Excell. 2018, 31, 1-18. [CrossRef]

42. Rovinelli, R.J.; Hambleton, R.K. On the use of content specialists in the assessment of criterion-referenced test item validity. In Proceedings of the 60th Annual Meeting of the American Educational Research Association, San Francisco, CA, USA, 19-23 April 1976; pp. 2-37.

43. Henrysson, S. Correction of item-total correlations in item analysis. Psychometrika 1963, 28, $211-218$. [CrossRef]

44. Bonett, D.G.; Wright, T.A. Cronbach's alpha reliability: Interval estimation, hypothesis testing, and sample size planning. J. Organ. Behav. 2015, 36, 3-15. [CrossRef]

45. Stevens, J.P. Applied Multivariate Statistics for the Social Sciences, 5th ed.; Routledge: London, UK, 2012.

46. Gillespie, D.F.; Mileti, D.S. Heterogeneous Samples in Organizational Research. Sociol. Methods Res. 1981, 9 , 375-388. [CrossRef]

47. Anderson, T.R.; Warkov, S. Organizational Size and Functional Complexity: A Study of Administration in Hospitals. Am. Sociol. Rev. 1961, 26, 23-28. [CrossRef]

48. Hinings, C.R.; Bryman, A. Size and the administrative component in churches. Hum. Relat. 1974, $27,457-475$. [CrossRef]

49. Chan, L.L.; Idris, N. Validity and reliability of the instrument using exploratory factor analysis and Cronbach's alpha. Int. J. Acad. Res. Bus. Soc. Sci. 2017, 7, 400-410.

50. Watkins, M.W. Exploratory factor analysis: A guide to best practice. J. Black Psychol. 2018, 44, $219-246$. [CrossRef]

51. Kumar, R.; Kumar, V.; Sharma, V.; Legendre, P.; Legendre, L.; Cattell, R.B.; Szymanska, E.; Gerretzen, J.; Engel, J.; Geurts, B. Common Factor Analysis Versus Principal Component Analysis: Differential Bias in Representing Model Parameters. Appl. Spectrosc. 2016, 70, 1598-1601.

52. Kyriazos, T.A. Applied psychometrics: Sample size and sample power considerations in factor analysis (EFA, CFA) and SEM in general. Psychology 2018, 9, 2207-2230. [CrossRef]

53. Turner, R.C.; Carlson, L. Indexes of item-objective congruence for multidimensional items. Int. J. Test. 2003, 3, 163-171. [CrossRef]

54. Hair, J.; Black, W.C.; Babin, B.J.; Anderson, R.E.; Tatham, R. Multivariate Data Analysis; Pearson Education: Upper Saddle River, NJ, USA, 2010. 
55. Kline, R.B. Principles and Practice of Structural Equation Modeling; Guilford publications: New York, NY, USA, 2015.

56. Kim, J.; Mueller, C.W. Factor Analysis: Statistical Methods and Practical Issues; Sage: London, UK, 1978.

57. Na-nan, K.; Saribut, S. Development and validation of an organisational commitment instrument for generation $Y$ employees in small and medium-sized enterprises in Thailand. Ind. Commer. Train. 2019, 51, 244-255. [CrossRef]

58. Zaiţ, A.; Bertea, P. Methods for testing discriminant validity. Manag. Mark. J. 2011, 9, 217-224.

59. Fornell, C.; Larcker, D.F. Structural Equation Models with Unobservable Variables and Measurement Error: Algebra and Statistics; SAGE Publications: Los Angeles, CA, USA, 1981.

60. Na-Nan, K.; Sanamthong, E. Self-efficacy and employee job performance: Mediating effects of perceived workplace support, motivation to transfer and transfer of training. Int. J. Qual. Reliab. Manag. 2019, 37, 1-17. [CrossRef]

61. Na-Nan, K. Employee work adjustment scale for small and medium-sized enterprises in Thailand. Int. J. Qual. Reliab. Manag. 2019, 36, 1284-1300. [CrossRef]

62. Riaz, S.; Xu, Y.; Hussain, S. Understanding employee innovative behavior and thriving at work: A Chinese perspective. Adm. Sci. 2018, 8, 46. [CrossRef]

63. Wang, Z.; Meng, L.; Cai, S. Servant leadership and innovative behavior: A moderated mediation. J. Manag. Psychol. 2019, 34, 505-518. [CrossRef]

64. van de Vrande, V.; de Jong, J.P.J.; Vanhaverbeke, W.; de Rochemont, M. Open innovation in SMEs: Trends, motives and management challenges. Technovation 2009, 29, 423-437. [CrossRef]

65. Yun, J.J.; Zhao, X.; Wu, J.; Yi, J.C.; Park, K.; Jung, W. Business Model, Open Innovation, and Sustainability in Car Sharing Industry-Comparing Three Economies. Sustainability 2020, 12, 1883. [CrossRef]

66. Yun, J.J.; Won, D.; Park, K. Entrepreneurial cyclical dynamics of open innovation. J. Evol. Econ. 2018, 28, 1151-1174. [CrossRef]

67. Chiaroni, D.; Chiesa, V.; Frattini, F. Unravelling the process from Closed to Open Innovation: Evidence from mature, asset-intensive industries. $R d$ Manag. 2010, 40, 222-245. [CrossRef]

68. Yun, J.J.; Liu, Z. Micro-and macro-dynamics of open innovation with a quadruple-helix model. Sustainability 2019, 11, 3301. [CrossRef]

69. Pukkeeree, P.; Na-Nan, K.; Wongsuwan, N. Effect of attainment value and positive thinking as moderators of employee engagement and innovative work behaviour. J. Open Innov. Technol. Mark. Complex. 2020, 6, 69. [CrossRef]

70. Schaufeli, W.B.; Bakker, A.B.; Salanova, M. The measurement of work engagement with a short questionnaire: A cross-national study. Educ. Psychol. Meas. 2006, 66, 701-716. [CrossRef]

71. Aguinis, H.; Henle, C.A.; Ostroff, C. Measurement in work and organizational psychology. In Handbook of Industrial, Work and Organizational Psychology; Anderson, N., Ones, D., Sinangil, H.K., Viswesvaran, C., Eds.; SAGE: London, UK, 2001; pp. 27-50.

72. Na-Nan, K.; Chaiprasit, K.; Pukkeeree, P. A validation of the performance management scale. Int. J. Qual. Reliab. Manag. 2018, 35, 1253-1267. [CrossRef]

(C) 2020 by the authors. Licensee MDPI, Basel, Switzerland. This article is an open access article distributed under the terms and conditions of the Creative Commons Attribution (CC BY) license (http://creativecommons.org/licenses/by/4.0/). 